\title{
DESIGN COMO PRÁTICA EDUCATIVA: ESTUDOS DE CASO DA APRENDIZAGEM BASEADA EM DESIGN
}

Bianca Maria Rêgo Martins

PUC-Rio / UniCarioca

maildabia@gmail.com

Rita Maria de Souza Couto

PUC-Rio

edesign@puc-rio.br

Resumo: O objeto deste estudo é a Aprendizagem Baseada em Design, pois partimos do princípio de que o modo pelo qual os designers problematizam situações complexas configuram certo tipo de inteligência que pode ser proveitosamente utilizada como prática educativa visando preparar os estudantes para os desafios da vida adulta contemporânea. Por este motivo, o estudo imbrica conhecimentos da área do Design e do campo da Educação. Discutimos os domínios do Design como Ciência do Artificial e como campo do saber que possui seus próprios modos de conhecer e proceder configurando-se, até mesmo, como certo tipo de cognição. Mais especificamente procuramos entender as características da Aprendizagem Baseada em Design através da exploração de casos onde esse tipo de prática educativa vem sendo inserida no contexto da Educação Básica, uma vez que em alguns países já existe essa tradição há algumas décadas. Logo, analisamos como distintas culturas incorporaram o design ao currículo, seja como área de conhecimento, seja como estratégia didática. Por fim, procuramos empreender aproximações ao conceito da Aprendizagem Baseada em Design explicitando as características comuns e mais evidentes nos casos investigados.

Palavras-chave: Aprendizagem Baseada em Design, Design Thinking; Design como inteligência; Design na Escola.

\footnotetext{
Abstract: The object of this study is Design-Based Learning, because we assume that the way designers thinks complex situations configure a kind of intelligence that can be usefully used as an educational practice aimed at preparing students for the challenges of contemporary adult life. So, the study articulates knowledges of the Design and the Education fields. We discussed the Design science as Artificial Science and as a knowledge' field that has its own ways of knowing and procedure even as certain kind of cognition. More specifically we seek to understand the features of DesignBased Learning through the exploration of cases where this type of educational practice has been inserted in the context of basic education,
} 
since in some countries there is this tradition for some decades. Therefore, we analyze how different cultures have incorporated design in the curriculum, either as a field of knowledge, whether as a teaching strategy. Finally, we discuss the concept of Design-Based Learning expressing the common and most obvious characteristics in the cases investigated.

Key-words: Design-Based Learning; Design Thinking; Design intelligence; Design in the Classroom.

\section{INTRODUÇÃO}

Sabe-se que o Design entendido como um conjunto de conhecimentos e procedimentos pode ser entendido como certo tipo de inteligência ou seja, como um modo de pensar/raciocinar, uma cognição voltada à concepção e prototipagem de novos objetos e/ou sistemas. Conforme os estudos de Simon (1969), pode-se dizer ainda que essa cognição enquadra-se como certo tipo de linguagem que visa a configuração e apreciação da Ciência do Artificial e como campo do Saber que possui seus próprios métodos de conhecer e proceder configurando-se, até mesmo, como uma cultura (ARCHER, 1979) ou inteligência (CROSS, 2010; GARDNER, 1983) que visa a configuração do futuro (BAYNES, 2010).

Conforme Lawson (2011) os designers problematizam seus projetos conciliando informações variadas e desconexas, conjugando necessidades de diferentes atores, trabalhando em equipe etc., e este tipo de raciocínio possui relevância para campos que ultrapassam o escopo restrito aos projetos de Design servindo, também, para a resolução de problemas da vida contemporânea.

Conforme Martins (2016) existe uma relação entre os princípios do Design e as características do paradigma educacional contemporâneo donde pode-se notar que a natureza desta atividade - seus princípios, metodologias, interações e práticas favorecem sua apropriação no contexto escolar como estratégia projetual integradora de conhecimentos multidimensionais e como meio de interrelacionar professores e alunos orientando-os no processo emancipatório de buscar soluções para problemas autênticos de seu contexto (comunidade, região etc.).

A partir destas perspectivas compreendemos que a natureza das atividades desenvolvidas durante um processo de Design pode favorecer seu enquadramento como um tipo especial de aprendizagem ativa e, por isso, argumentamos que estratégias de Design podem e devem ser utilizadas na escola como práticas educativas. Nesse sentido a Aprendizagem Baseada em Projetos de Design como estratégia educativa, assim como os próprios projetos de Design, favorece a abordagem multidimensional apropriada à resolução problemas do mundo contemporâneo, realiza-se através de trabalho em equipe, desenvolve a abordagem do problema em cooperação com o usuário, oportuniza a utilização de ferramentas de gestão e plano de ação - ambas importantes para a vida adulta, é interdisciplinar, aguça a atenção sensível e o senso estético e direciona-se à imaginar soluções esboçando ideias abstratas para ações futuras, ou seja, ativa a imaginação com um propósito específico.

Neste artigo discutimos casos em que esse tipo de estratégia educativa vem sendo inserida no contexto da Educação Básica. Assim, investigamos como distintas 
culturas incorporaram o Design ao currículo, seja como área de conhecimento, seja como estratégia didática. Para este levantamento foram desenvolvidas pesquisas bibliográficas e documentais.

\section{DESENVOLVIMENTO}

\section{1 - O Design como Disciplina}

Neste contexto analisamos o Design entendido como uma área do Saber dentro da escola. Conforme Simon (1969), o estudo da Ciência do Artificial inclui o estudo do Design, uma vez sendo evidente a onipresença das coisas artificiais na vida contemporânea, o autor advoga a favor do ensino das Ciências do Artificial na Educação Básica.

\subsection{1 - O currículo inglês}

Conforme Raizen et al (1995), no mundo ocidental, o ensino do Design na Educação Básica de crianças e jovens, foi implementado por muitos anos em casos isolados, mas somente nos anos 80 , na Inglaterra, veio a se constituir como um movimento nacional organizado. Segundo o autor, naquele país a abordagem como componente curricular foi primeiramente nomeada de Craft, Design and Technology (CDT), uma vez que emergiu da tradição do fazer manual. Num segundo momento incorporou um viés mais construtivista e hoje o currículo em questão recebe o nome de Design and Technology (D\&T). Esse fator difere do modo pelo qual o Design é incorporado ao Ensino Fundamental nos EUA e em outros países, onde o mesmo aparece como uma estratégia integradora de conhecimentos que pode ser implementada em diferentes momentos e níveis de complexidade.

No contexto inglês Baynes (2010) comenta que desde 1973 Bruce Archer já discutia o papel do Design e da Educação em Design voltados aos desafios do futuro: super população, poluição e sustentabilidade. Estes desafios reforçam a importância da Educação em Design na escola primária e secundária. Archer e Baynes identificam o raciocínio em Design (ou o Design Thinking) como um aspecto cognitivo relacionado à habilidade de projetar e prototipar, ou seja, habilidade de imaginar alternativas viáveis para o futuro. Baynes vem desenvolvendo desde a década de 80 um estudo sobre as diretrizes do campo da Educação em Design no ensino fundamental onde existem dois pontos-chave a) a natureza da atividade imaginativa do Design e sua significância para a educação e b) a questão da graficidade (graphicacy) e o aspecto cognitivo do Design relacionado a habilidade de prototipar.

Estes dois aspectos são abordados no currículo inglês através de duas disciplinas: Artes e Design e Design e Tecnologia, ambas disciplinas obrigatórias dos 5 aos 14 anos (Key Stages 1, 2 e 3).

\section{2 - O Design como catalizador da aprendizagem}

Diferentemente do contexto do Design como Disciplina, os casos abaixo ilustram a presença do Design no contexto escolar como estratégia de integração de conhecimentos através da realização de projetos.

\subsection{1 - A Educação através do Design - Meredith Davis}

Meredith Davis, Arte Educadora e Designer, desenvolveu em conjunto com outros pesquisadores um currículo para 500 escolas públicas de Michigan que baseia- 
se em estratégias integradas de projetos de Design visando o desenvolvimento pelos próprios alunos de comunicações, objetos e ambientes.

Davis et al (1997) também desenvolveram um inventário sobre a aprendizagem através do Design nos EUA nas três décadas anteriores. Para os autores o Design pode ser entendido como uma área de investigação e um modo de questionamento que engaja diferentes estilos de aprendizagem e faz uma conexão direta entre temas escolares e a resolução de problemas da vida cotidiana. Na abordagem dos autores o Design é utilizado como estratégia de ensino para diferentes idades e níveis, não sendo visto somente como assunto relacionado ao ensino médio ou técnico. Para Davis et al, o uso do Design como modo de investigação aponta para:

- escolha da forma mais adequada dos artefatos (que podem ser comunicações visuais, produtos e soluções ambientais);

- considerar as necessidades e desejos das pessoas afetadas;

- o contexto social, físico e cultural onde o produto se insere.

As atividades propostas podem ser ativas (desenvolver uma solução para um problema) e/ou reflexivas (refletir e/ou apreciar objetos ou contextos) onde os estudantes aplicam estratégias de resolução de problemas e devem ser capazes de aprender questões mais amplas do processo de trabalho.

Para Davis, existe uma congruência entre o modo de pensar e projetar utilizado pelos designers e as demandas que os estudantes encontrarão no mundo adulto. Isso justifica a expansão e aplicação dos métodos e da pedagogia do Design para o ensino de diferentes áreas do conhecimento na Educação Básica.

Para atender as demandas do futuro as diferentes nações precisarão de
profissionais e cidadãos criativos que possam superar as limitações dos modos
tradicionais de solução de problemas, que sejam capazes de inventar
estratégias apropriadas para abordar novas situações e que tenham a
habilidade de se adaptar às mudanças. Para ter sucesso, esses profissionais do
futuro precisarão adquirir novas informações e habilidades antes
inimaginadas. Precisarão reconhecer que são indivíduos inseridos num
sistema mais amplo e que suas ações terão consequências imediatas no
espaço/tempo. Como cidadãos, ainda precisarão fortalecer a estrutura de
comunidades que serão cultural e socialmente mais diversas. E quando
participantes de uma decisão comunitária, precisarão honrar seus valores
pessoais respeitando os valores dos outros. (DAVIS, 1997, p. 2)

Davis comenta que todas essas são características enfatizadas na educação de um designer e proporcionam uma formação para rápidas mudanças nos processos de solução de problemas. Esse seria o componente criativo do método científico onde presume-se que existe mais de uma solução apropriada para um problema e muitos caminhos para cada alternativa. Conforme Davis (op.cit), nos modos de projetar inerentes ao Design não existe hierarquia entre habilidades físicas e cognitivas. Para os designers construir/prototipar são modos de conhecer. Eles analisam um problema desenvolvendo protótipos, diagramas, caminhando pelo entorno, esboçando ideias, estatísticas ou escrevendo. Designers são fluentes em diferentes meios de reflexão: imagens, palavras e números, e métodos de comunicar, narrar, recombinar 
experiências para usos futuros. Seu processo é iterativo, e os meios de reflexão podem ser alterados em novos problemas e oportunidades.

Conforme Davis, (2004), existem termos diferentes utilizados para se referir aos vários tipos de Educação através do Design. Mesmo nas escolas de Educação Infantil americanas (pré-K12), as finalidades do ensino de Design são diversas. É improvável que um programa simples possa abarcar muitas modalidades, assim como é difícil que as distintas modalidades possam ser igualmente eficazes a diferentes propósitos. Vejamos no quadro abaixo as diferentes modalidades da educação através do Design enfatizadas por Davis:

\begin{tabular}{|l|l|}
\hline $\begin{array}{l}\text { Atividades básica em } \\
\text { Design 2D e 3D }\end{array}$ & $\begin{array}{l}\text { Atividades que consistem em composições abstratas ou aplicação dos } \\
\text { elementos e princípios do Design (por exemplo, cor, textura, ritmo, } \\
\text { equilíbrio, e etc.) para atribuições sem usuários ou contextos específicos de } \\
\text { uso. }\end{array}$ \\
\hline $\begin{array}{l}\text { Conscientização de } \\
\text { consumidores }\end{array}$ & $\begin{array}{l}\text { Atividades que ampliem o entendimento dos alunos sobre como o Design se } \\
\text { relaciona aos contextos físico, psicológico, social, cultural e tecnológico } \\
\text { auxiliando a escolhas inteligentes em suas vidas diárias sobre comunicações, } \\
\text { produtos e ambientes. }\end{array}$ \\
\hline $\begin{array}{l}\text { Ensino aprendizagem } \\
\text { baseado em projeto } \\
\text { de Design }\end{array}$ & $\begin{array}{l}\text { Atividades que utilizam os metodologias da prática projetual e da pedagogia } \\
\text { da Educação em Design para ensinar ou aprender qualquer assunto. }\end{array}$ \\
\hline $\begin{array}{l}\text { Educação em Design } \\
\text { Pre-professional }\end{array}$ & $\begin{array}{l}\text { Atividades que familiarizam os alunos com o trabalho dos profissionais de } \\
\text { Design replicando alguns aspectos da prática projetual desta carreira. }\end{array}$ \\
\hline
\end{tabular}

Quadro 1: Modalidades de educação através do Design.

Fonte: Davis, Meredith. Education by Design. In: Arts Education Policy Review. Vol. 105, No. 5, May/June 2004.

\subsection{2 - O Design Based Learning - Doreen Nelson}

Doreen Nelson, é professora e supervisora do Laboratório de Aprendizagem Baseada em Design do Art Center College of Design em Pasadena onde instaurou o primeiro mestrado do país nesta área. Nelson foi pioneira na instauração da Aprendizagem Baseada em Design, há 35 anos, com um método que produz melhoria no desempenho do aluno no Ensino Fundamental e Médio (K-12). Seu método é fruto de pesquisas e ensino nas escolas americanas destes dois seguimentos. A proposta é inverter a ênfase da aprendizagem tradicional e envolver os alunos em pensamentos mais complexos através da construção de artefatos físicos que representam os conceitos desenvolvidos no currículo

No Design Based Learning (DBL) elaborado por Nelson, os alunos começam projetando e construindo um objeto nunca antes visto que já sensibiliza para as competências a serem construídas durante o curso. Além de construir, os alunos precisam explicar como o objeto funciona e a qual contexto pertence e somente após esta sensibilização através do planejamento e construção ocorrem as aulas tradicionais para desenvolver os conhecimentos trabalhados naquele segmento.

O Design Based Learning fundamenta-se, ainda, na ideia de que este objeto nunca antes visto consiste em uma comunidade, uma vez que esta é composta de peças individuais que se inter-relacionam. Nelson acredita que comunidades são conceitos imediatamente compreensíveis, flexíveis e amigáveis uma vez que todos podem desenvolver uma concepção/opinião a respeito da mesma. Dependendo do nível de ensino, a comunidade pode ser uma casa, uma cidade, uma vila, um negócio, 
um governo, uma civilização, um posto avançado ou uma utopia. Os alunos aprendem sobre sistemas e organizações da comunidade na intenção de descobrir o que a comunidade precisa para funcionar adequadamente. Algumas indagações poderiam ser: Que elementos compõe esta comunidade? O que cada elemento precisa, e como ele interage com os outros? O que acontece se houver um colapso? Quem pode ajudar, e como?

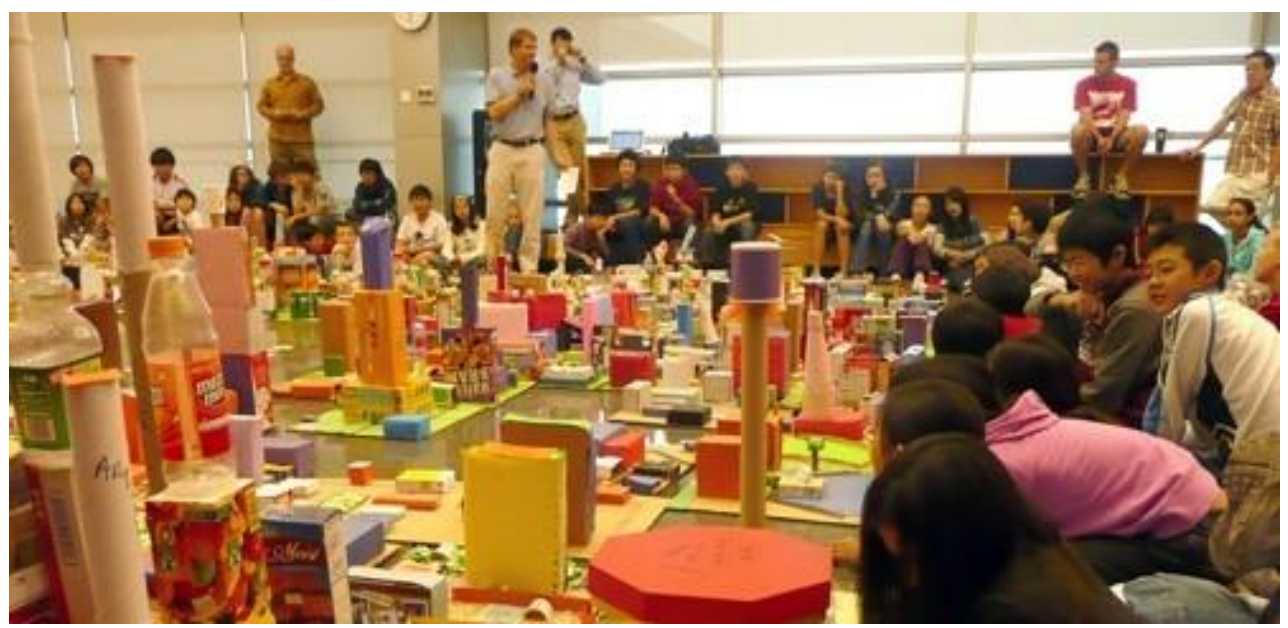

Figura 1: Um objeto/comunidade nunca antes vista

Fonte: Doreen Nelson, 2004. Disponível em:

https://www.cpp.edu/ dnelson/methodology/6.5steps.html. Acessado em: 02/02/2015.

\subsection{3 - O Design Based Teaching - Charles Burnette}

O pesquisador Charles Burnette considera que

É mais importante para os alunos aprender a pensar com clareza e agir de forma eficaz para alcançar objetivos de valor do que aprender fatos ou técnicas que podem tornar-se obsoletos. Os jovens precisam desenvolver habilidades de pensar e agir de forma eficaz que possam ser utilizadas ao longo de suas vidas em qualquer assunto ou situação. (BURNETTE, 2005, acessado em 19/02/2014).

Charles Burnette, arquiteto, Doutor em Design, decano e pesquisador entre as universidades do Texas e Pensilvânia, desenvolve nos EUA pesquisas sobre Educação baseada em Design desde 1989. Desde 1990 oferece cursos de capacitação de professores para implementação da metodologia do Design Based Teaching.

Para Burnette (2005), o processo de pensamento construtivo do Design Thinking deveria ser o foco da Educação Básica atual pois o Design Thinking fornece uma experiência de aprendizagem motivadora e envolvente porque incorpora interesses e habilidades variados através de experiências de aprendizagem baseadas em projetos que desafiam a iniciativa pessoal. Deste modo, estilos de aprendizagem individuais surgem naturalmente ao responder a outros estilos de aprendizagem.

\section{Para o autor o Design Thinking:}

- E multidisciplinar e aplicável a qualquer assunto;

- Integra imaginação e pensamento analítico; 
- Enfatiza o pensamento construtivo sobre retenção factual;

- Conecta a vivência de uma experiência à uma ação responsável;

- Incentiva a avaliação objetiva e de valores;

- Promove a cooperação, socialização e compreensão humanística;

- Promove o conhecimento através de experiências de aprendizagem criativas.
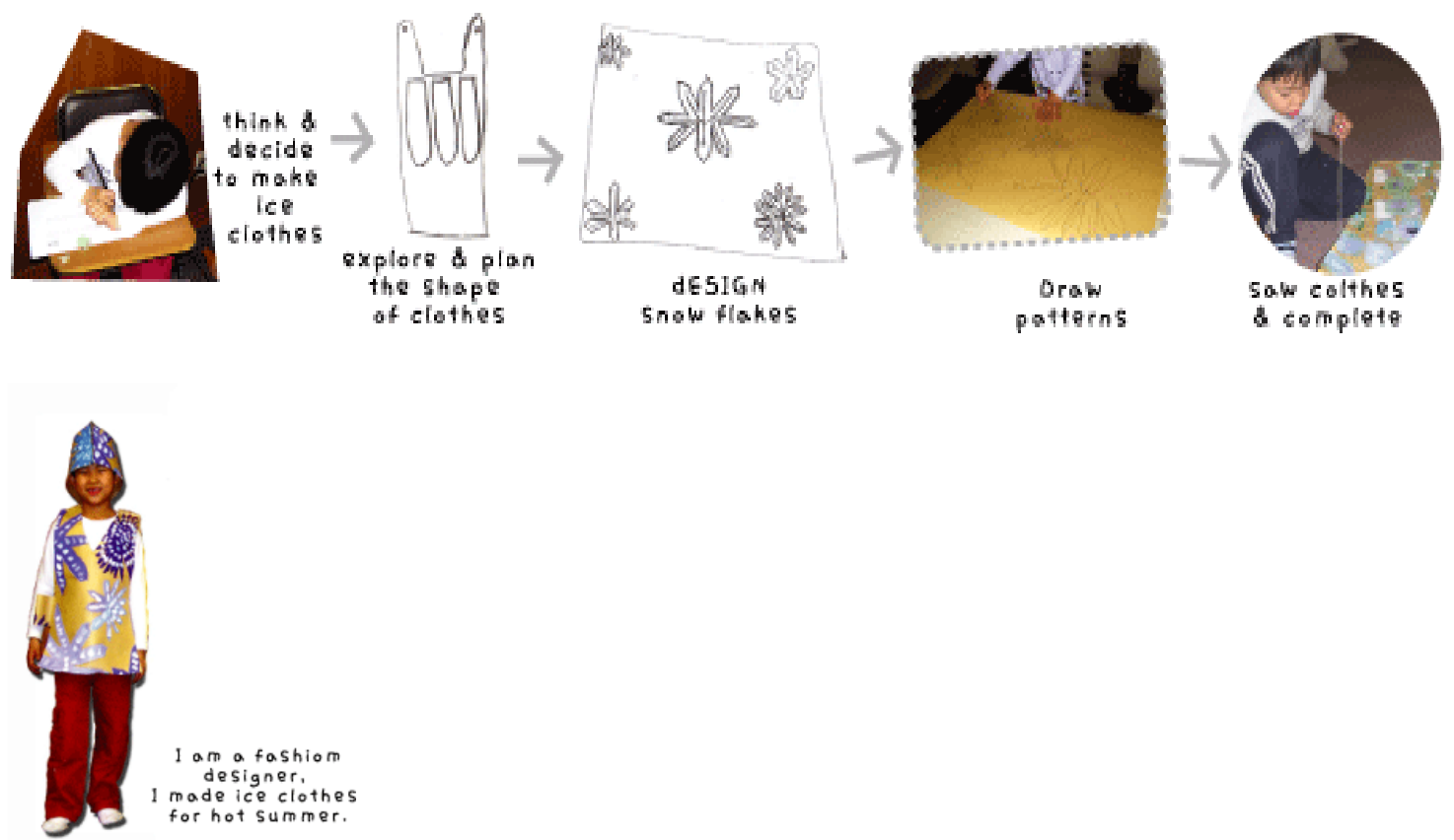

Figura 2: Processo de construção de um objeto por uma criança através da utilização da metodologia do Design Thinking.

Fonte: Charles Burnette, 2005. Disponível em:

http://www.idesignthinking.com/01whyteach/01whyteach.html. Acessado em: 02/02/2015.

Sabe-se que as respostas naturais dos seres humanos às condições da vida diária implicam na elaboração de necessidades e desejos que demandam soluções de Design. Para Burnette (2005), o Design Thinking integra diferentes saberes e atitudes uma vez que as questões de motivação, competências linguísticas, cognição, compreensão, comportamento, autoestima e bem-estar social podem ser conduzidas através das diferentes formas de pensar durante o projeto. $O$ autor pontua que os modos pelos quais alunos buscam seus próprios objetivos revelam os interesses e aptidões individuais e também a influência das emoções sobre o pensamento. Para o autor o Design Thinking também contribui para identificação de problemas de desenvolvimento da criança antecipando, se for necessário, o encaminhamento a abordagens terapêuticas. Ele acredita que o Design Thinking pode conectar áreas tão distintas como: linguagens, arte, engenharia, ciências, sociedade, cultura e história, dentre outras.

Por estes motivos o Design Based Teaching de Burnette fundamenta-se em desenvolver estilos de pensamento que estão associados às etapas de um processo projetual que pode se aplicar a diferentes situações e objetivos, como comentado. Vejamos um quadro explicativo desses estilos de pensamento associados às ações de um processo projetual de Design: 


\begin{tabular}{|l|l|l|l|l|}
\hline AÇÃO & PENSAMENTO & $\begin{array}{l}\text { OBJETIVO } \\
\text { PROJETUAL }\end{array}$ & $\begin{array}{l}\text { OBJETIVO } \\
\text { EDUCACIONAL }\end{array}$ & ARGUMENTO \\
\hline Intenção & Intencional & $\begin{array}{l}\text { Estabelecer as } \\
\text { necessidades e } \\
\text { objetivos }\end{array}$ & Orientar & $\begin{array}{l}\text { As crianças aprendem melhor quando } \\
\text { buscam ativamente o que eles querem } \\
\text { e precisam. }\end{array}$ \\
\hline Definição & Referencial & $\begin{array}{l}\text { Nomear, listar e } \\
\text { descrever o que } \\
\text { está envolvido }\end{array}$ & $\begin{array}{l}\text { Identificar e } \\
\text { descrever }\end{array}$ & $\begin{array}{l}\text { As crianças aprendem melhor quando } \\
\text { usam palavras e imagens que tenham } \\
\text { significado para elas. }\end{array}$ \\
\hline Exploração & Relacional & $\begin{array}{l}\text { Imaginar, organizar } \\
\text { e analisar } \\
\text { possibilidades }\end{array}$ & $\begin{array}{l}\text { Descobrir e } \\
\text { analisar }\end{array}$ & $\begin{array}{l}\text { As crianças aprendem melhor quando } \\
\text { estão livres para explorar as } \\
\text { associações entre as coisas. }\end{array}$ \\
\hline Sugestão & Formativo & $\begin{array}{l}\text { Decidir, apresentar } \\
\text { e explicar a } \\
\text { proposta }\end{array}$ & $\begin{array}{l}\text { Apresentar e } \\
\text { explicar }\end{array}$ & $\begin{array}{l}\text { As crianças aprendem melhor quando } \\
\text { expressam e explicam seus } \\
\text { sentimentos, crenças e ideias. }\end{array}$ \\
\hline Inovação & Processual & $\begin{array}{l}\text { Melhorar } \\
\text { continuamente a } \\
\text { produção proposta }\end{array}$ & $\begin{array}{l}\text { Tentativa e erro; } \\
\text { construir }\end{array}$ & $\begin{array}{l}\text { As crianças aprendem melhor quando } \\
\text { tentam fazer o que percebem como } \\
\text { necessidade e uma melhor forma de } \\
\text { resolvê-la. }\end{array}$ \\
\hline Avaliação & Avaliativo & $\begin{array}{l}\text { Julgar, medir e } \\
\text { avaliar o sucesso }\end{array}$ & $\begin{array}{l}\text { Aprendizagem } \\
\text { incidental }\end{array}$ & $\begin{array}{l}\text { As crianças aprendem melhor quando } \\
\text { avaliam a sua experiência, a sua } \\
\text { aprendizagem e os seus resultados. }\end{array}$ \\
\hline $\begin{array}{l}\text { Aprendiza- } \\
\text { gem }\end{array}$ & Reflexivo & $\begin{array}{l}\text { Lembrar, integrar e } \\
\text { aplicar o que foi } \\
\text { aprendido }\end{array}$ & $\begin{array}{l}\text { Lembrar e narrar } \\
\text { As crianças aprendem melhor quando } \\
\text { vivenciam algo que eles querem } \\
\text { lembrar. }\end{array}$ \\
\hline
\end{tabular}

Quadro 2 - Estilos de pensamento que estão associados às etapas de um processo projetual Fonte: Burnette, 2005, acessado em 19/02/2015.

Um ponto interessante em Burnette é que ele conjuga todos os estilos de pensamento e ciências integrando-os sem que haja a preponderância de algum deles.

\subsection{4 - A Educação através do Design - EDaDE - Antônio Fontoura}

A Educação através do Design - EdaDe - é uma proposta pedagógica baseada na pedagogia da ação e no construtivismo, apresentada como tese de doutorado de

Antônio Martiniano Fontoura em 2002, na Universidade Federal de Santa Catarina. O EDaDe parte dos seguintes princípios:

- A formação das crianças pode ser complementada e enriquecida através de atividades de Design;

- Atividades de Design estimulam o pensamento criativo/abdutivo das crianças;

- O processo de ensino aprendizagem, dessa forma, torna-se mais dinâmico, significativo, autônomo e interdisciplinar.

- Estas atividades permitem o desenvolvimento de habilidades manuais e mentais e propiciam o pensamento crítico e construtivo.

De modo prático, a EdaDe utiliza-se de atividades de Design, compostas por tarefas ou ações menores, e seu objetivo é desenvolver e aplicar habilidades e construir conhecimentos através de práticas orientadas pelo Design. Deve, portanto, produzir resultados práticos e gerar oportunidades de ensino e aprendizagem. Esta pedagogia adota o princípio de que toda criança vem à escola com uma bagagem própria de conhecimentos que, através das atividades de Design, serão integrados aos conhecimentos trazidos pelos colegas e aos desafios que a escola pode oferecer. A interação entre os diversos conhecimentos, visando um objetivo comum (a abordagem 
de um problema), pode ser viabilizada por um processo que caracteriza a atividade de Design.

Para o EDaDE, uma atividade de Design deve estimular o uso de habilidades mentais e manuais, como imaginar (soluções), externar (ideias) e usar (ferramentas e recursos). Habilidades mentais, portanto, fazem referência à criação, percepção, resolução de problemas, verbalização, julgamento e vários tipos de pensamento (como o crítico e o criativo, ambos fundamentais para o Design); enquanto habilidades manuais estão ligadas à aplicação e desenvolvimento de conhecimentos tecnológicos: construção, utilização de equipamentos e ferramentas, representações gráficas. Estas habilidades são inerentes aos humanos, comuns desde a infância, e são também consideradas habilidades de Design. Portanto, no projeto de objetos, tanto a construção material do produto quanto as necessidades humanas são elementos a serem considerados. As relações entre estes elementos são oportunidades de a criança pensar, criar e construir as soluções que integram os componentes do problema, desenvolvendo assim suas habilidades.

No contexto da EdaDe, as atividades são divididas em três tipos:

\begin{tabular}{|l|l|}
\hline TIPO DE ATIVIDADE & HABILIDADE DESENVOLVIDA \\
\hline $\begin{array}{l}\text { Atividades de Investigação e Análise } \\
\text { - AIA }\end{array}$ & $\begin{array}{l}\text { Desenvolvimento de habilidades mentais, como investigação, pesquisa, } \\
\text { análise, avaliação e geração de ideias etc. }\end{array}$ \\
\hline Tarefas Práticas de Design - TPD & $\begin{array}{l}\text { Desenvolvimento de habilidades manuais, como uso de ferramentas, } \\
\text { equipamentos, materiais etc. }\end{array}$ \\
\hline $\begin{array}{l}\text { Atividades de Design e Construção - } \\
\text { ADC }\end{array}$ & $\begin{array}{l}\text { Atividades complexas que desenvolvem diversas habilidades } \\
\text { simultaneamente }\end{array}$ \\
\hline
\end{tabular}

Quadro 3: Baseado em FONTOURA, Antônio Martiniano. Tese de doutorado. EdaDe: a educação de crianças e jovens através do design. Orientadora: Alice, Pereira. Florianópolis: [s.n.], 2002.

Dentre os modelos de aplicação da EdaDe expostos na tese de Fontoura, um deles aborda o Design como tema transversal às outras disciplinas, integrando os conteúdos. Conforme Fontoura, o Design poderia figurar, portanto, como recurso didático da educação para a cidadania, quando aborda questões da cultura material e consumo consciente e estabelece relações com atividades profissionais. $O$ autor sugere alguns possíveis blocos de conteúdo a serem trabalhados pela EdaDe: Design e Sociedade; Design e Cultura; Design e Consumo; Design e Meio Ambiente; e Design e Tecnologia. Estes blocos abordariam conteúdos como: impactos do Design na sociedade; formação da cultura material; critérios de Design para o consumo responsável e consciente; impactos ambientais e as consequências ecológicas da produção industrial; desenvolvimento tecnológico e suas implicações no Design dos produtos, objetos e ambiente; etc. (FONTOURA, 2002)

\subsection{5 - Os Estudos e Pesquisas do LIDE - PUC-Rio}

O Laboratório Interdisciplinar de Design/Educação - LIDE, pertencente ao Departamento de Artes \& Design - DAD - da PUC-Rio, coordenado pela Profa. Dra. Rita Maria de Souza Couto, teve início no ano de 1997 com uma equipe constituída por professores pesquisadores e alunos de graduação e pós-graduação em Design da PUCRio. Em linhas gerais o LIDE desenvolve projetos e pesquisas onde haja 
participação do designer em trabalhos voltados para a Educação, em qualquer nível Pré-escolar, Fundamental, Médio, Superior e Avançado -, bem como para estudos e pesquisas relacionadas ao ensino de Design nos âmbitos extra universitário, técnico, extensão, de graduação e de pós-graduação. Para este estudo nos interessa destacar dois projetos desenvolvidos pelo LIDE: o projeto PIU/Design e o projeto Educação Infantil: uma proposta em ação sob o olhar do Design.

\section{PIU Design}

O PIU Design foi resultado de uma pesquisa realizada no LIDE em 1999 junto a uma Escola Municipal no Rio de Janeiro, onde foi aplicada a metodologia de ensino de projeto em Design, utilizada por alunos de graduação da PUC-Rio, baseada no enfoque metodológico do Design em Parceria. A experiência de desenvolver o processo projetual de Design com o objetivo de levar os alunos do 4으 ano do Ensino Fundamental 1 a identificar problemas na própria escola e propor soluções para os mesmos contribuiu para a identificação de meios e procedimentos que permitissem levar noções de Design para o âmbito pré-universitário.

\section{Workshop de Projeto e Workshop de Criatividade para alunos do Ensino Médio:}

A vivência acima relatada possibilitou a elaboração e aplicação de dois workshops - o primeiro de projeto e o segundo de criatividade - que foram implementados com alunos do 20 e 3ㅇ ano do Ensino Médio. A pesquisa constatou a relevância da aprendizagem do processo projetual do Design no Ensino Fundamental e médio como forma, não só de disseminar a ampla aplicação dos conhecimentos da área como também a possibilidade de contribuir para o desenvolvimento do potencial criativo dos alunos, potencializando sua autonomia e seu senso crítico a partir da identificação e da solução de uma situação real de projeto, em parceira com um grupo social. Com base nesta experiência foi oficializado o funcionamento, no Departamento de Artes da PUC-Rio, o Programa de Iniciação Universitária em Design - PIU/Design.

As atividades realizadas com o Ensino Médio incluíram alunos do 20 e 3응, com idade média entre 15 e 18 anos. Foram atendidos vários colégios particulares da

Zona Sul do Rio de Janeiro e cada workshop teve duração de seis horas. 0 objetivo da atividade era desenvolver todas as fases do processo projetual do Design em apenas uma tarde de trabalho.

\section{LIDE/PUC-Rio - Educação Infantil: uma proposta em ação sob o olhar do Design}

Esta pesquisa está sendo desenvolvida pela equipe do LIDE/PUC-Rio desde 2013. O projeto teve como ponto de partida a Cooperação Técnica e Científica entre o Ministério de Educação, Cultura e Formação de São Tomé e Príncipe - MECF, o UNICEF e PUC-Rio com o objetivo de contribuir para a melhor aprendizagem e bem-estar geral das crianças e a construção de habilidades e capacidades técnicas para garantir, alcançar e manter uma Educação Infantil de qualidade em São Tomé e Príncipe.

O projeto, que tem finalização prevista para 2017, compreende a elaboração de conteúdo curricular para a Educação Infantil, a definição de uma metodologia de ensino para esse segmento, a realização de cursos de reciclagem para Educadores e Auxiliares, o projeto de materiais didáticos e a ressignificação de espaços físicos de Jardins de Infância de São Tomé e Príncipe. Desenvolve-se por meio de um diálogo interdisciplinar entre Design e Educação ilustrando várias formas onde a atividade do 
Design pode participar dos processos de ensino aprendizagem, potencializando a construção de conhecimento para meio da configuração de artefatos, ambientes e estratégias educativas. O currículo proposto apresenta conteúdos vivos e concretos, portanto indissociáveis da realidade social. A ênfase é posta na relação entre conteúdo e significação do mesmo para o aluno. Ainda, esta reestruturação foi planejada pensando-se em seus desdobramentos metodológicos.

\subsection{6 - A figura do Atelierista e os Espaços Relacionais - Escolas Reggio Emília}

A pedagogia Reggio Emília instituiu-se no nordeste da Itália após o término da Segunda Guerra e, conforme Rinaldi (2012), sua origem remonta à um grupo de mães da região que decide erguer e administrar uma escola com uma pedagogia da mais alta qualidade. O local é a Villa Cella, próxima a Reggio Emilia. À esta iniciativa reúne-se o jovem pedagogo Loris Malaguzzi que constitui um princípio de ensino no qual não existem disciplinas formais e onde todas as atividades pedagógicas se desenvolvem por meio de projetos. Estes projetos surgem através das ideias dos próprios alunos e são desenvolvidos por meio de diferentes linguagens. Isso que dizer que tais projetos não são antecipadamente planejados pelos professores. O princípio utilizado é a Pedagogia da Escuta (ou Pedagogia Reggio Emília) que foi sistematizada pelo educador italiano e vincula-se a tudo o que a linguagem visual pode apresentar. Segundo Rinaldi (2012), este exemplo serviu de fonte de apoio e inspiração para a Educação Infantil de países de contextos bem diferentes como Suécia e Senegal, Dinamarca e Nova Zelândia, Espanha e Estados Unidos etc.

Conforme Rinaldi (2012), Loris Malaguzzi dialoga com a pedagogia de vanguarda da época: Piaget, Vigotsyk, Freinet, autores que não haviam ainda sido traduzidos na Itália. Assim, a construção pedagógica das escolas se concretiza dentro de uma perspectiva sócio-construtivista onde o conhecimento se constrói através da ação do sujeito, no contexto, junto com a inovação social e com a cultura do grupo, ou seja, as crianças aprendem pelas experiências e nas experiências da ação e do fazer.

Para os objetivos deste estudo, uma das questões mais relevantes que pudemos observar da Pedagogia Reggio Emilia é a de que os professores atuam em parceria com o atelierista, ou seja, um profissional que favorece a consolidação de pontes entre as diversas descobertas da criança. Esta parceria com o atelierista permite que a criança seja estimulada pela ideia de experimentar, de descobrir o mundo e os outros a partir do manejo das diferentes linguagens às quais é apresentada. $O$ atelierista também é:

concretamente, quem cuida da dimensão estética e cultural dos projetos e do ambiente, realiza uma gestão criativa dos projetos didáticos, por meio do estímulo no plano expressivo e cognitivo, cuida da documentação e da interpretação dos processos cognitivos das crianças junto com professores e pedagogos, participa e planeja da organização de exposições, de laboratórios de expressão com crianças e, as vezes, com os pais; e colabora com outros colegas em projetos que se relacionam, por exemplo, com diversas experiências da e na cidade. Daí se deduz que não é uma função que pode ser facilmente definida com conjunto de atribuições rígidas. Pelo contrário, é uma função extremamente flexível e é essa flexibilidade que a torna única e importante. (FARIA e CRIADO, 2007, p. 12). 


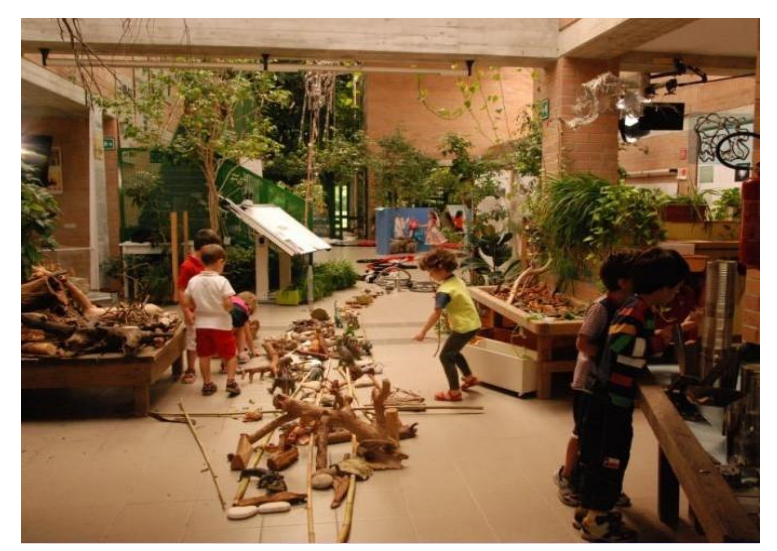

Figura 3: Praça da Escola Comunale Dell'infanzia Ernesto Balducci di Reggio Emilia. Acessado em: 13/01/2015.

Ainda na proposta de valorizar a experiência dos alunos, as salas que acolhem os projetos das crianças não são arrumadas para o dia seguinte. A ideia é que as crianças possam revisitar suas criações e mesmo dar continuidade às suas pesquisas, sendo este um fio condutor da aprendizagem.

Três princípios da proposta pedagógica de Loris Malaguzzi:

1. Múltiplas linguagens: as crianças podem compartilhar seus conhecimentos e saberes, sua criatividade e imaginação por meio de múltiplas linguagens, sem enfatizar nenhuma. As múltiplas linguagens evidenciam-se através do desenho, do canto, da dança, da pintura, da interpretação, enfim, divulgadas por distintas passagens que se somam na execução do projeto e nos saberes que são construídos. Anotar, fotografar, gravar e filmar são partes principais da rotina.

2. Interdisciplinaridade: o mundo de conhecimentos não está dividido em assuntos escolares, mas é um grupo único, onde certas áreas são sugeridas por meio de projetos como uma matéria de trabalho.

3. Parceria: A interação entre o adulto e a criança deve ser uma parceria, na qual interesses e envolvimentos recíprocos devem permanecer e interagir para que um objetivo comum seja alcançado: o saber.

\section{CONCLUSÃO}

\section{Aproximações ao conceito Aprendizagem Baseada em Design}

Nosso olhar para estes casos nos levaram à elaboração de aproximações ao conceito da Aprendizagem Baseada em Design como sendo uma estratégia pedagógica que articula o objetivo da aprendizagem à proposição de uma solução de Projeto de Design que pode ter profundidade e ênfase apropriada à necessidade em questão.

A Aprendizagem Baseada em Design realiza-se no paradigma híbrido da PósModernidade e é influenciada pelos preceitos de um mundo globalizado e que articula novas modalidades de ensino da Ciência, da Tecnologia, da Arte, das Humanidades e da Educação Ambiental. Neste contexto, como já visto, os educadores preocupam-se em propor estratégias de aprendizagem baseadas na abordagem de problemas sociais, ambientais, culturais, étnicos, dentre outros - reais e complexos da comunidade onde a escola está inserida. 
Logo, esta modalidade de aprendizagem interessa à uma proposta educativa que articule os conhecimentos curriculares para favorecer a abordagem de problemas sobre populações crescentes; finitude das reservas naturais; padrões insustentáveis de consumo, produção, construção e transportes; ênfase em um ensino para o desenvolvimento sustentável integrando: meio-ambiente, população, desenvolvimento socioeconômico, produtos, embalagens e construções mais amigáveis.

Por isso, a Aprendizagem Baseada em Design concebe a comunidade ao redor da escola como um livro-texto onde a natureza dos problemas demanda um conhecimento interdisciplinar que incorpore também o conhecimento já construído por esta própria comunidade.

A Aprendizagem Baseada em Design, de acordo com os preceitos de uma aprendizagem atenta às demandas da vida contemporânea, também valoriza a igualdade de oportunidades, a educação integral, o desenvolvimento de competências, o respeito à diversidade, a abordagem interdisciplinar e multidimensional do conhecimento e a aprendizagem atenta aos afetos e a apreensão sensível dos estímulos do cotidiano.

Caracterizando-se como uma pedagogia ativa e baseada na resolução de projetos através da problematização própria do Design Thinking esta é uma prática de aprendizagem que valoriza:

- O aluno como protagonista da aula

- O conhecimento prévio do aluno

- A aprendizagem autônoma e investigativa

- A comportamento proativo

- O professor reflexivo e colaborativo

- A comunidade escolar e suas redondezas como fonte de problematização

- O trabalho em equipe

- A inovação curricular

- A interdisciplinaridade

- A autoavaliação

- A aplicação do conhecimento fora da escola

Para respaldar, mais uma vez, a validade desta abordagem pedagógica na vida contemporânea, citamos o relatório Perspectivas para a Política Educacional realizado pela OECD - Organização para a Cooperação Econômica e para o Desenvolvimento, em 2015. Neste relatório percebe-se que as políticas educacionais que mais surtiram efeito - dentre 450 políticas educacionais realizadas entre os anos de 2008 e 2014 pelos vários países signatários da OECD - foram aquelas focadas nos estudantes e na aprendizagem e, além disso, as que fortalecem a capacidade pedagógica dos professores.

Esta constatação justifica a presença de estudos que estejam focados em elaborar propostas para incorporar a Aprendizagem Baseada em Design na formação docente. 


\section{REFERÊNCIAS}

BAYNES, K. Models of Change: The future of Design education. In: Design and Technology Education: An International Journal. Loughborough, Vol. 15, No. 3, pgs. 10-17, 2010.

BURNETTE, C. IDESIGN - 7 ways of Design Thinking, A teacher resource. Disponível em: $<w w w$. idesignthinking.com> Acesso em: abril de 2014.

COUTO, R. Movimento Interdisciplinar de designers Brasileiros em Busca de Educação Avançada. Rio de Janeiro, 1997. 220p. Tese de Doutorado Departameto de Educação, PUC-Rio.

CROSS, N.; Designerly ways of knowing, Springer-Verlag, London, 2006

DAVIS, Meredith. et al. Design as a Catalyst for Learning. Virgínia: ASCD, 1997. . Education by Design. In: Arts Education Policy Review. Vol. 105, No. 5, May/June 2004.

FONTOURA, A. M. Tese de doutorado. EdaDe: a educação de crianças e jovens através do Design. Orientadora: Alice Theresinha Cybis Pereira. Florianópolis: [s.n.], 2002.

HERNANDEZ, F.; VENTURA, M.. A organização do currículo por projetos de trabalho. Porto Alegre: Artmed, 1998.

JAPIASSU, H., MARCONDES, D. Dicionário Básico de Filosofia. Rio de janeiro: Jorge Zahar, 2001.

LAWSON, B. Como arquitetos e designers pensam. São Paulo: Oficina de textos, 2011.

MARTINS, Bianca. Design da informação de situações de utilidade pública. Orientadora: Rita Maria de Souza Couto. -- Rio de Janeiro: PUC--Rio, Departamento de Artes \& Design, 2007.

MORIN, E. Introdução ao pensamento complexo. 3. ed. Porto Alegre: Sulina, 2007

E. O método II: A vida da vida. Lisboa: Publicações Europa-América, 1999

OECD. Education Policy Outlook 2015 - Making Reforms Happen. OECD, 2015.

RAIZEN, S. et al. Technology education in the classroom. Understanding the designed world. San Francisco: Jossey-Bass Publishers, 1995.

RIBEIRO, R. de C. A aprendizagem baseada em problemas (PBL): uma implementação na educação em engenharia. Tese (Doutorado) - UFSC, Florianópolis, 2005.

RITTEL H., WEBBER M. Dilemmas in a General Theory of Planning. Amsterdam: Elsevier Scientific Publishing Company, 1973.

RINALDI, C. Diálogos com Reggio Emilia: escutar, investigar e aprender. São Paulo: Paz e Terra, 2012.

ROYAL COLLEGE OF ART. Design in General Education. London: Royal College of Art, 1979. SIMON, H. The science of the artificial, Cambridge (MA.): MIT Press, 1969. 